\title{
Fatty liver incidence and predictive variables
}

\author{
Akira Tsuneto $^{1,2}$, Ayumi Hida ${ }^{2}$, Nobuko Sera ${ }^{2}$, Misa Imaizumi ${ }^{2}$, Shinichiro Ichimaru ${ }^{2}$, Eiji Nakashima ${ }^{3}$, \\ Shinji Seto ${ }^{1}$, Koji Maemura ${ }^{1}$ and Masazumi Akahoshi ${ }^{2}$
}

\begin{abstract}
Although fatty liver predicts ischemic heart disease, the incidence and predictors of fatty liver need examination. The objective of this study was to determine fatty liver incidence and predictive variables. Using abdominal ultrasonography, we followed biennially through 2007 (mean follow-up, $11.6 \pm 4.6$ years) 1635 Nagasaki atomic bomb survivors (606 men) without fatty liver at baseline (November 1990 through October 1992). We examined potential predictive variables with the Cox proportional hazard model and longitudinal trends with the Wilcoxon rank-sum test. In all, 323 (124 men) new fatty liver cases were diagnosed. The incidence was $19.9 / 1000$ person-years (22.3 for men, 18.6 for women) and peaked in the sixth decade of life. After controlling for age, sex, and smoking and drinking habits, obesity (relative risk (RR), 2.93; 95\% confidence interval (Cl), 2.33-3.69, $P<0.001)$, low high-density lipoprotein-cholesterol (RR, 1.87; 95\% Cl, 1.42-2.47; $P<0.001)$, hypertriglyceridemia (RR, 2.49; 95\% Cl, 1.96-3.15; $P<0.001$ ), glucose intolerance (RR, $1.51 ; 95 \% \mathrm{Cl}, 1.09-2.10$; $\boldsymbol{P}=0.013$ ) and hypertension (RR, 1.63; 95\% Cl, 1.30-2.04; $\boldsymbol{P}<0.001)$ were predictive of fatty liver. In multivariate analysis including all variables, obesity (RR, $2.55 ; 95 \% \mathrm{Cl}, 1.93-3.38 ; \boldsymbol{P}<0.001$ ), hypertriglyceridemia (RR, $1.92 ; 95 \% \mathrm{Cl}$, 1.41-2.62; $P<0.001$ ) and hypertension (RR, $1.31 ; 95 \% \mathrm{Cl}, 1.01-1.71 ; P=0.046)$ remained predictive. In fatty liver cases, body mass index and serum triglycerides, but not systolic or diastolic blood pressure, increased significantly and steadily up to the time of the diagnosis. Obesity, hypertriglyceridemia and, to a lesser extent, hypertension might serve as predictive variables for fatty liver.
\end{abstract}

Hypertension Research (2010) 33, 638-643; doi:10.1038/hr.2010.45; published online 9 April 2010

Keywords: fatty liver; hypertriglyceridemia; incidence; obesity

\section{INTRODUCTION}

The recent increase in obesity caused by excess food intake has led to an increased incidence in metabolic syndrome and visceral fat accumulation, ${ }^{1-3}$ both of which are associated with non-alcoholic fatty liver disease. ${ }^{4-11}$ As non-alcoholic fatty liver disease is also associated with the classical coronary risk factors of obesity, hypertension, dyslipidemia and glucose intolerance, ${ }^{4,7,8,10-15}$ non-alcoholic fatty liver disease serves as a surrogate marker for visceral fat accumulation or metabolic syndrome.

Non-alcoholic fatty liver disease correlates with the remodeling of coronary artery lesions or lipid core plaques when evaluated by multislice computed tomography and with coronary artery stenosis evaluated by coronary angiography. ${ }^{16,17}$ Moreover, non- alcoholic fatty liver disease might be a stronger predictor than metabolic syndrome of cardiovascular disease. ${ }^{18}$ In obese children, non-alcoholic fatty liver disease is associated with dyslipidemia, hypertension and glucose intolerance, and predicts development of these conditions. ${ }^{5,7}$ Few reports, however, describe the incidence of fatty liver and its predictive variables. ${ }^{19,20}$ In this study, we selected atomic bomb survivors in Nagasaki who were confirmed by abdominal ultrasonography during
1990 to 1992 (baseline) as not having fatty liver and followed them through 2007 to examine the incidence of, and predictive variables for, fatty liver.

\section{METHODS}

Subjects

As part of the follow-up program of the Radiation Effects Research Foundation (RERF, formerly the Atomic Bomb Casualty Commission), 7564 atomic bomb survivors (3374 men) have undergone biennial examinations in Nagasaki since 1958. A detailed description of this program has been published elsewhere (Atomic Bomb Casualty Commission, Technical Report and RERF, Research Plan for RERF Adult Health Study, Hiroshima and Nagasaki, RERF Research Protocol 2-75, 1975). RERFs Research Protocol Review Committee and the Human Investigation Committee approved the original program in 1975 and this study in 2008 (RP-A 08-08).

At the baseline examination (November 1990 through October 1992), 2015 subjects underwent clinical examination, biochemical measurements and abdominal ultrasonographic examination. The 123 fatty liver cases that were detected then were excluded from this study, as were subjects who were positive $(n=167)$ or indeterminate $(n=90)$ for hepatitis B virus surface antigen and/or

\footnotetext{
${ }^{1}$ Department of Cardiovascular Medicine, Course of Medical and Dental Sciences, Graduate School of Biomedical Sciences, Nagasaki University, Sakamoto, Nagasaki, Japan; ${ }^{2}$ Department of Clinical Studies, Radiation Effects Research Foundation, Nakagawa, Nagasaki, Japan and ${ }^{3}$ Department of Statistics, Radiation Effects Research Foundation, Minami-ku, Hiroshima, Japan

Correspondence: Dr A Tsuneto, Department of Cardiovascular Medicine, Course of Medical and Dental Sciences, Graduate School of Biomedical Sciences, Nagasaki University, 1-7-1 Sakamoto, Nagasaki 852-8120, Japan.

E-mail: atsuneto@rerf.or.jp
}

Received 30 November 2009; revised 12 January 2010; accepted 15 February 2010; published online 9 April 2010 
anti-hepatitis $C$ virus antibody. We included the remaining 1635 subjects in this study.

\section{Baseline data collection}

At each examination, a trained nurse collected clinical and life-style (past and current smoking and drinking habits) information. The nurse also measured sitting blood pressure $(\mathrm{mm} \mathrm{Hg})$ on the left arm with a sphygmomanometer after a sufficient sedentary period using the first Korotkoff phase for systolic blood pressure (SBP) and the fifth for diastolic blood pressure (DBP). We classified subjects as having hypertension if their SBP was $\geqslant 130 \mathrm{~mm} \mathrm{Hg}$ and/or their DBP was $\geqslant 85 \mathrm{mmHg}$ from a preventive point of view based on Guidelines for the Management of Hypertension (JSH2009) and metabolic syndrome. ${ }^{21,22}$

Standing height (in $\mathrm{m}$ ) and body weight (in $\mathrm{kg}$ ) were measured without socks and outer clothing. Body mass index (BMI) was calculated as body weight divided by the square of the standing height $\left(\mathrm{kg} \mathrm{m}^{-2}\right)$. Obesity was defined as a BMI of $\geqslant 25 \mathrm{~kg} \mathrm{~m}^{-2}$, in accordance with the definition of the Japan Society for the Study of Obesity.

Fasting blood samples were drawn for biochemical measurements. Serum total cholesterol (mg per $100 \mathrm{ml}$ ), high-density lipoprotein cholesterol (HDLcholesterol, mg per $100 \mathrm{ml}$ ), serum triglyceride $(\mathrm{mg}$ per $100 \mathrm{ml})$, and fasting blood glucose (mg per $100 \mathrm{ml}$ ) were measured by an automated procedure (Hitachi 7050 and 7170S; Hitachi, Tokyo, Japan) with quality control monitored in accordance with the College of American Pathologists (Northfield, IL, USA). Hypercholesterolemia was defined as total serum cholesterol $\geqslant 220 \mathrm{mg}$ per $100 \mathrm{ml}$, low HDL-cholesterol as serum HDL-cholesterol $<40 \mathrm{mg}$ per $100 \mathrm{ml}$ and hypertriglyceridemia as serum triglyceride $\geqslant 150 \mathrm{mg}$ per $100 \mathrm{ml}$. Subjects with a fasting blood glucose $\geqslant 110 \mathrm{mg}$ per $100 \mathrm{ml}$ and those undergoing medical treatment for diabetes mellitus or impaired glucose tolerance were defined as having glucose intolerance.

Radiologists, without making reference to the subjects' history or data, conducted abdominal ultrasonographic examinations using an Aloka SSD-650, SSD-2000 (Aloka, Tokyo, Japan) and GE LOGIQ-500 (GE Healthcare Japan, Tokyo, Japan) and diagnosed fatty liver when there was accentuation of liverkidney contrast, blurring of the hepatic vessel wall or deep attenuation of echogenicity. ${ }^{23}$ Ultrasonography is a sensitive and reasonably accurate diagnostic tool for assessing fat infiltration of the liver. Others have found $83 \%$ sensitivity and $100 \%$ specificity in comparison with histology, and $100 \%$ sensitivity and $56 \%$ specificity in comparison with $\mathrm{CT}^{23,24}$ In this study, a second radiologist blindly reviewed 40 films originally classified as fatty liver and 80 films from age- and sex-matched persons that were not so classified. The positive agreement rate by the second rater was $80 \%$ and the negative agreement rate was $95 \%$, yielding a kappa coefficient of agreement of $0.77 .{ }^{25}$

\section{Follow-up}

All subjects visited RERF biennially and underwent the same clinical, biochemical and ultrasonographic examinations as at the baseline examination.
Follow-up began on the date of the baseline examination and ended on the date of the diagnosis of fatty liver, the date of death or 31 December 2007, whichever came first. The criteria for fatty liver were the same as at baseline examination.

\section{Radiation dose}

We based total radiation dose on Dosimetry System 2002 (DS02) with a weighting factor of 10 for neutrons relative to $\gamma$ rays. ${ }^{26}$ To reduce radiation effect estimation bias, ${ }^{27}$ we adjusted the gamma and neutron doses for $35 \%$ dose error after truncation at $4 \mathrm{~Gy}$ for doses over $4 \mathrm{~Gy}$. The mean radiation dose was 0.517 Gy (range, $0-3.455$ ).

\section{Statistical analysis}

We calculated the incidence of fatty liver using the person-year method. We used the Wilcoxon rank-sum test to compare continuous variables (age, BMI, total cholesterol, HDL-cholesterol, serum triglycerides, SBP, DBP and radiation dose) and the $\chi^{2}$ test to compare prevalences (sex, smoking and drinking habits, and glucose intolerance) between incident fatty liver cases and non-incident fatty liver cases at baseline. We used the Cox proportional hazard model to examine the predictive variables (obesity, hypercholesterolemia, low HDLcholesterolemia, hypertriglyceridemia, glucose intolerance and hypertension) for incident fatty liver after controlling for age, sex, smoking and drinking habits, and atomic bomb radiation dose.

When fatty liver was diagnosed in someone for the first time at follow-up, we randomly selected two sex- and age-matched controls from non-incident fatty liver cases. For example, if fatty liver was diagnosed for the first time in 1995 in a 63-year-old male, we randomly selected two male controls who were aged 60-64 years in 1995. As the predictive variables for fatty liver were obesity, hypertriglyceridemia and hypertension (see multivariate analysis in results section), we plotted BMI, serum triglycerides, SBP and DBP at $-6,-4,-2$ (before the diagnosis), 0 (at the diagnosis), 2, 4 and 6 years after the diagnosis in cases and at the corresponding times in controls, and we used the Wilcoxon rank-sum test to compare the values. We set a $P$-value of $<0.05$ for over-all significance and of $<0.0084(\fallingdotseq 0.05 / 6)$ for a Bonferroni-type multiple comparison in the analysis of BMI, triglycerides, SBP and DBP. We conducted all analyses using SAS software running on a UNIX System (SAS/STAT Software, Release 9.0., SAS Institute, Cary, NC, USA).

\section{RESULTS}

Table 1 shows the baseline characteristics of the 1635 subjects by sex. As indicated from the mean age of our study subjects, our study cohort consisted of middle aged/elderly subjects (-49-year old, 113 subjects; 50-59 years old, 284 subjects; $60-69$ years old, 863 subjects; 70-79 years old, 289 subjects; 80 - years old, 86 subjects). Among them, 323 (124 men) were newly diagnosed with fatty liver during the follow-up period. The mean follow-up period was 11.6 years (s.d., 4.6; median, 14.0; range, 1.3-17.1).

Table 1 Baseline characteristics of the study population by sex

\begin{tabular}{|c|c|c|c|c|}
\hline Risk factors & Total $(\mathrm{n}=1635)$ & Men $(n=606)$ & Women $(\mathrm{n}=1029)$ & $\mathrm{P}$ \\
\hline Age & $63.1 \pm 8.9$ & $62.4 \pm 9.6$ & $63.4 \pm 8.4$ & 0.002 \\
\hline Smoking (\%) & 34.6 & 76.9 & 9.7 & $<0.001$ \\
\hline Drinking (\%) & 41.0 & 78.7 & 18.8 & $<0.001$ \\
\hline $\mathrm{BMI}\left(\mathrm{kg} \mathrm{m}^{-2}\right)$ & $22.5 \pm 3.0$ & $22.2 \pm 2.7$ & $22.7 \pm 3.1$ & 0.003 \\
\hline T-chol (mg per $100 \mathrm{ml}$ ) & $206.5 \pm 34.7$ & $193.1 \pm 30.6$ & $214.4 \pm 34.5$ & $<0.001$ \\
\hline HDL-C (mg per 100 ml) & $54.9 \pm 14.5$ & $52.0 \pm 14.7$ & $56.7 \pm 14.0$ & $<0.001$ \\
\hline TG (mg per $100 \mathrm{ml}$ ) & $115.3 \pm 61.0$ & $122.6 \pm 72.3$ & $110.9 \pm 52.9$ & 0.004 \\
\hline Glucose intolerance (\%) & 10.5 & 14.2 & 8.4 & $<0.001$ \\
\hline $\mathrm{SBP}(\mathrm{mm} \mathrm{Hg})$ & $127.3 \pm 19.4$ & $129.4 \pm 18.2$ & $126.1 \pm 20.0$ & $<0.001$ \\
\hline $\mathrm{DBP}(\mathrm{mm} \mathrm{Hg})$ & $79.3 \pm 11.0$ & $81.2 \pm 10.4$ & $78.1 \pm 11.2$ & $<0.001$ \\
\hline Atomic radiation dose (mGy) ${ }^{a}$ & $522.6 \pm 741.7(n=1077)$ & $527.0 \pm 719.8(n=403)$ & $520.0 \pm 754.8(n=674)$ & 0.42 \\
\hline
\end{tabular}

Abbreviations: BMI, body mass index; DBP, diastolic blood pressure; HDL-C, high-density lipoprotein cholesterol; SBP, systolic blood pressure; T-chol, total cholesterol; TG, triglyceride. ${ }^{a}$ As radiation dose was not determined in all subjects, the numbers of subjects was reduced to 1077 (403 men, 674 women).

Atomic radiation dose, atomic bomb radiation dose estimated by RERF 2002 criterion. Unless otherwise indicated, values are expressed as the mean \pm s.d. 
Table 2 Baseline characteristics of incident fatty liver cases and nonincident fatty liver cases

\begin{tabular}{lccc}
\hline & $\begin{array}{c}\text { Incident fatty } \\
\text { liver }\end{array}$ & $\begin{array}{c}\text { Non-incident } \\
\text { fatty liver }\end{array}$ & $\mathrm{P}$ \\
\hline Number & 323 & 1312 & \\
Age & $59.0 \pm 7.3$ & $64.1 \pm 9.0$ & $<0.001$ \\
Sex (men \%) & 38.4 & 36.7 & 0.58 \\
Smoking (\%) & 34.4 & 34.7 & 0.92 \\
Drinking (\%) & 45.2 & 39.9 & 0.09 \\
BMI (kg m-2) & $24.1 \pm 2.8$ & $22.1 \pm 2.9$ & $<0.001$ \\
T-chol (mg per 100 ml) & $210.2 \pm 35.1$ & $205.6 \pm 34.5$ & 0.029 \\
HDL-C (mg per 100 ml) & $50.9 \pm 13.1$ & $56.0 \pm 14.6$ & $<0.001$ \\
TG (mg per 100 ml) & $143.1 \pm 85.0$ & $108.4 \pm 51.3$ & $<0.001$ \\
Glucose intolerance (\%) & 13.0 & 9.9 & 0.10 \\
Hypertension (\%) & 56.3 & 47.4 & 0.004 \\
Atomic radiation dose & $510.1 \pm 726.6$ & $525.6 \pm 745.6$ & 0.92 \\
(mGy) & $(n=214)$ & $(n=863)$ & \\
\hline
\end{tabular}

Abbreviations are the same as in Table 1. Unless otherwise indicated, values are expressed as the mean \pm s.d.

Table 2 shows the baseline characteristics of subjects who did and did not develop fatty liver. The two groups did not differ in sex ratio, smoking or drinking habits, prevalence of glucose intolerance, or radiation dose. The group that developed fatty liver, however, had higher mean values for BMI, total cholesterol level and triglyceride level, a higher prevalence of hypertension, and lower mean values for age and HDL-cholesterol level. The incidence of fatty liver per 1000 person-years was 19.9 (22.3 for men, 18.6 for women). It peaked in the sixth decade of life and decreased thereafter in both sexes (Figure 1).

In Cox's proportional hazard model adjusted for age, sex, and smoking and drinking habits, obesity, low HDL-cholesterol, hypertriglyceridemia, glucose intolerance, and hypertension were statistically significant predictors of fatty liver (Table 3 ). In multivariate analysis including all variables, obesity, hypertriglyceridemia and hypertension remained positive predictors (Table 3). Radiation dose was not a predictive variable.

Subjects who developed fatty liver had significantly higher BMIs and serum triglyceride levels than control subjects throughout the 12year study period (Figures 2a and b). Moreover, their BMI levels increased steadily and significantly during the 6 years before the diagnosis to the diagnosis $\left(23.9 \pm 2.8 \mathrm{~kg} \mathrm{~m}^{-2}\right.$ at -6 years and $24.1 \pm 3.0 \mathrm{~kg} \mathrm{~m}^{-2}$ at -4 years to $25.0 \pm 3.0 \mathrm{~kg} \mathrm{~m}^{-2}$ at 0 years $(P<0.001$ for two intervals $))$ and remained elevated, while the level remained constant in controls (Figure 2a). Similarly, serum triglycerides levels in those who developed fatty liver increased steadily and significantly up to the time of diagnosis $(130.0 \pm 54.6 \mathrm{mg}$ per $100 \mathrm{ml}$ at -6 years to $159.2 \pm 71.9 \mathrm{mg}$ per $100 \mathrm{ml}$ at 0 years, $P<0.001)$ and remained elevated, while the level remained constant in controls (Figure 2b). Although hypertension was a predictive variable, SBP and DBP were not consistently higher in cases than in controls and did not increase significantly during the observation period (Figures $2 \mathrm{c}$ and $\mathrm{d}$ ).

\section{DISCUSSION}

In this study of 1635 Nagasaki atomic bomb survivors who were followed for 12 years, our finding of an incidence of fatty liver of $19.9 / 1000$ person-years was similar to the incidence of $18.5 / 1000$ person-years reported by Bedogni et al. ${ }^{19}$ for a general Italian population followed for a median time of 8.5 years. In a study of

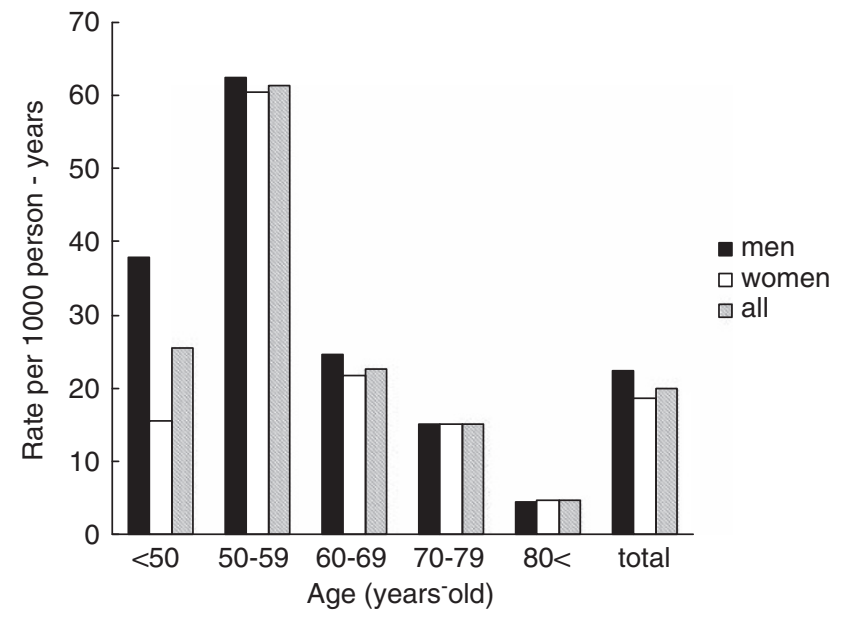

Figure 1 Incidence of fatty liver. Black bars represent men, white bars women and gray bars all subjects.

3147 Japanese adults who consumed $<20 \mathrm{~g}$ of ethanol per day, Hamaguchi et al. ${ }^{20}$ reported that $10 \%$ of subject developed nonalcoholic fatty liver disease at follow-up examination ( $1.13 \pm 0.35$ years later). And while we did not find a sex difference in the development of fatty liver, Hamaguchi et al. reported a higher incidence among men, which might be explained by the fact that the mean age of participants at baseline examination in their cohort study (48.1 years for men, 46.6 for women) was younger than it was in our study (62.4 years for men, 63.4 for women). Indeed, as shown in Figure 1, the incidence of fatty liver in participants $<50$ years old was higher in men than in women.

Our finding that the incidence of fatty liver in both sexes peaked in the sixth decade of life and decreased thereafter may follow from that fact that BMI generally follows that age pattern. ${ }^{28,29}$ Our calculation of fatty liver incidence in participants $<50$ years old, however, was based on only four male and two female incident cases. That may have biased our results, leading to the possibility that peak fatty liver incidence might occur in the fifth decade instead of the sixth. Cohort studies including younger subjects are needed to confirm the age of peak fatty liver incidence.

That obesity, low HDL-cholesterol, hypertriglyceridemia, glucose intolerance and hypertension-classic risk factors for cardiovascular disease-were predictive of fatty liver in Cox regression analysis (after controlling for age, sex, and smoking and drinking habits) and that obesity, hypertriglyceridemia and hypertension remained predictive in multivariate Cox regression analyses fit in with our understanding of the pathophysiological pathway of fatty liver. ${ }^{12,30}$ Obesity (from excess nutrition intake) leads to visceral fat accumulation. Visceral fat has high metabolic activity and releases free fatty acids and adipokines such as leptin, tumor necrosis factor- $\alpha$, and adiponectin. ${ }^{31-34}$ Insulin resistance caused by increasing tumor necrosis factor- $\alpha$ secretion or decreasing adiponectin secretion induces hypertension and glucose intolerance. ${ }^{31}$ Leptin and angiotensinogen secreted from visceral fat also induces hypertension. ${ }^{33}$ In this way, visceral fat accumulation associated with obesity serves as a risk factor for hypertension and glucose intolerance. In contrast, free fatty acids released from visceral fat enter the liver through the portal vein, and increased free fatty acid influx from the portal vein stimulates triglyceride synthesis in liver. Fatty liver is the condition of triglyceride deposited in liver, and fatty 
Table 3 Relative risk of predictive variables for fatty liver by means of multiple Cox's regression analysis

\begin{tabular}{|c|c|c|c|c|}
\hline & $R R(95 \% C l)^{a}$ & $P$ & $R R(95 \% C l)^{\mathrm{b}}$ & $P$ \\
\hline Sex (women) & & & $0.93(0.61-1.42)$ & 0.73 \\
\hline Drinking & & & $0.95(0.68-1.32)$ & 0.75 \\
\hline Obesity (BMI $\left.\geqslant 25 \mathrm{~kg} \mathrm{~m}^{-2}\right)$ & $2.93(2.33-3.69)$ & $<0.001$ & $2.55(1.93-3.38)$ & $<0.001$ \\
\hline Hypercholesterolemia (T-chol $\geqslant 220 \mathrm{mg}$ per $100 \mathrm{ml}$ ) & $1.12(0.88-1.42)$ & 0.35 & $0.98(0.73-1.30)$ & 0.88 \\
\hline Glucose intolerance & $1.51(1.09-2.10)$ & 0.013 & $1.31(0.90-1.90)$ & 0.16 \\
\hline Hypertension & $1.63(1.30-2.04)$ & $<0.001$ & $1.31(1.01-1.71)$ & 0.046 \\
\hline Atomic radiation dose (mGy) $(n=1077)$ & $0.99(0.83-1.18)$ & 0.89 & $0.92(0.78-1.10)$ & 0.38 \\
\hline
\end{tabular}

Abbreviations: $\mathrm{Cl}$, confidence interval; $\mathrm{RR}$, relative risk.

Other abbreviations are the same as in Table 1.

${ }^{a}$ Adjusted for age, sex, smoking and drinking habits.

bAll variables are included.
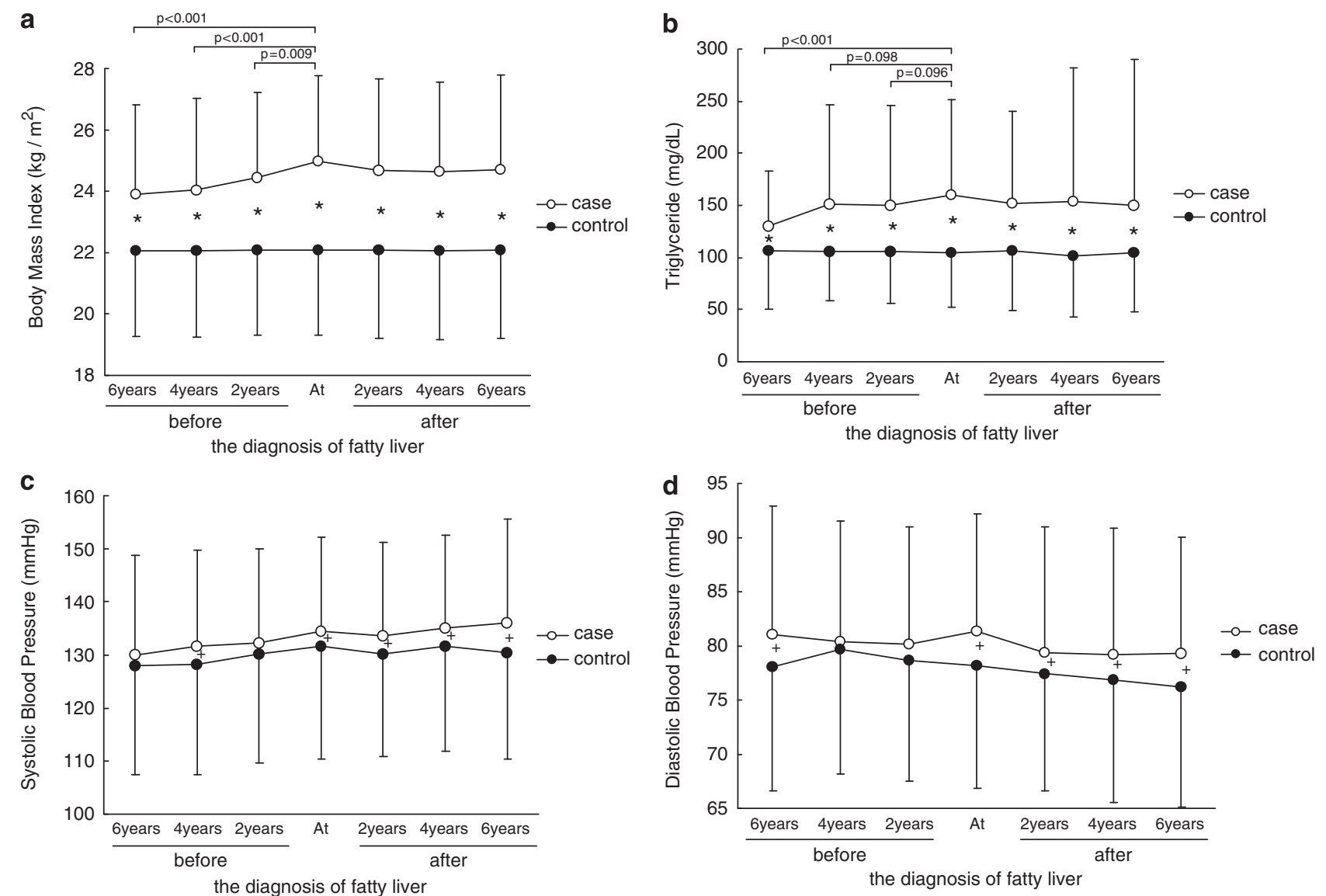

Figure 2 (a) BMI trends. Values are expressed as means \pm s.d. Comparisons were made by means of analysis of covariance. ${ }^{*} P<0.001$ between fatty liver cases and controls. (b) Triglyceride trends. Values are expressed as means \pm s.d. Comparisons were made by means of analysis of covariance. ${ }^{*} P<0.001$ between fatty liver cases and controls. (c) SBP trend. Values are expressed as means \pm s.d. Comparisons were made by means of analysis of covariance. $+P<0.05$ between fatty liver cases and controls. (d) DBP trend. Values are expressed as means \pm s.d. Comparisons were made by means of analysis of covariance. ${ }^{+} P<0.05$ between fatty liver cases and controls.

liver is thus a surrogate marker of visceral fat accumulation and clusters the classic risk factors for cardiovascular disease-obesity, hypertension, dyslipidemia and glucose intolerance.

Hamaguchi et al. ${ }^{20}$ reported that metabolic syndrome and weight gain were predictive of non-alcoholic fatty liver disease development.
Although we could not evaluate whether metabolic syndrome predicted the development of fatty liver because we did not measure waist circumference at baseline examination, our results are consistent with their results in the following aspects; (1) coronary risk factors associated with metabolic syndrome, that is, obesity, dyslipidemia 
and hypertension, predict the development of fatty liver, and; (2) increases in BMI and serum triglycerides are related to the development of fatty liver as suggested by observed trends (Figure 2).

\section{LIMITATIONS}

(1) The mean age of study participants was $63.1 \pm 8.9$ at baseline (November 1990 through October 1992), which means that many of our study participants had taken excess nutrition since their middle age. Thus, our calculated age of peak incidence may shift to older age and our overall incidence estimate (19.9/1000 person-years) may be calculated to be low. Further studies including younger subjects are necessary to evaluate fatty liver incidence in the contemporary era of excess nutrition intake.

(2) Our subjects were atomic bomb survivors in Nagasaki, Japan, which means that our results might not be generalizable. Radiation dose was not a predictive variable for incident fatty liver, however, so we believe that the present results can be generalized, although further studies in non-atomic bomb survivors are necessary.

(3) Although we incorporated alcohol intake into the analysis and found it not to be a predictive variable for incident fatty liver, we could not negate the possibility that fatty liver cases related to alcohol intake were included in the study because we did not take amount of alcohol intake into account. (For the diagnosis of non-alcoholic fatty liver, alcohol intake should not exceed 20 g per day $^{35}$ ).

\section{CONCLUSION}

In this middle aged/elderly subjects cohort, fatty liver incidence (19.9/ 1000 person-years) peaked in the sixth decade of life and decreased thereafter. Although obesity, hypertriglyceridemia and hypertension were predictive of fatty liver, BMI and serum triglyceride level, but not SBP or DBP, increased steadily up to the time of diagnosis. These data suggest that obesity and hypertriglyceridemia, rather than hypertension, are closely associated with development of fatty liver.

\section{ACKNOWLEDGEMENTS}

We thank Mr Tomohiro Ikeda for general assistance and Dr Miriam Bloom (SciWrite Biomedical Writing and Editing Services) for professional editing. The Radiation Effects Research Foundation (RERF), Hiroshima and Nagasaki, Japan is a private, non-profit foundation funded by the Japanese Ministry of Health, Labour and Welfare (MHLW) and the US Department of Energy (DOE), the latter in part through the National Academy of Sciences. This publication was supported by RERF Research Protocol A 08-08.

1 McKeown NM, Meigs JB, Liu S, Saltzman E, Wilson PW, Jacques PF. Carbohydrate nutrition, insulin resistance, and the prevalence of the metabolic syndrome in the Framingham Offspring Cohort. Diabetes Care 2004; 27: 538-546.

2 Ford ES, Giles WH, Dietz WH. Prevalence of the metabolic syndrome among US adults: findings from the third National Health and Nutrition Examination Survey. JAMA 2002; 287: 356-359.

3 Wirfalt E, Hedblad B, Gullberg B, Mattisson I, Andren C, Rosander U, Janzon L, Berglund G. Food patterns and components of the metabolic syndrome in men and women: a cross-sectional study within the Malmo diet and cancer cohort. Am J Epidemiol 2001; 154: 1150-1159.

4 Tsai CH, Li TC, Lin CC. Metabolic syndrome as a risk factor for nonalcoholic fatty liver disease. South Med J 2008; 101: 900-905.

5 Schwimmer JB, Pardee PE, Lavine JE, Blumkin AK, Cook S. Cardiovascular risk factors and the metabolic syndrome in pediatric nonalcoholic fatty liver disease. Circulation 2008; 118: 277-283.
6 Eguchi Y, Eguchi T, Mizuta T, Ide Y, Yasutake T, Iwakiri R, Hisatomi A, Ozaki I, Yamamoto K, Kitajima Y, Kawaguchi Y, Kuroki S, Ono N. Visceral fat accumulation and insulin resistance are important factors in nonalcoholic fatty liver disease. J Gastroenterol 2006; 41: 462-469.

7 Fan JG, Li F, Cai XB, Peng YD, Ao QH, Gao Y. Effects of nonalcoholic fatty liver disease on the development of metabolic disorders. J Gastroenterol Hepatol 2007; 22: 1086-1091.

8 Omagari K, Kadokawa Y, Masuda J, Egawa I, Sawa T, Hazama H, Ohba K, Isomoto H, Mizuta Y, Hayashida K, Murase K, Kadota T, Murata I, Kohno S. Fatty liver in nonalcoholic non-overweight Japanese adults: incidence and clinical characteristics. J Gastroenterol Hepatol 2002; 17: 1098-1105.

9 Hamaguchi M, Kojima T, Itoh Y, Harano Y, Fujii K, Nakajima T, Kato T, Takeda N, Okuda J, Ida K, Kawahito Y, Yoshikawa T, Okanoue T. The severity of ultrasonographic findings in nonalcoholic fatty liver disease reflects the metabolic syndrome and visceral fat accumulation. Am J Gastroenterol 2007; 102: 2708-2715.

10 Amarapurkar D, Kamani P, Patel N, Gupte P, Kumar P, Agal S, Baijal R, Lala S, Chaudhary D, Deshpande A. Prevalence of non-alcoholic fatty liver disease: population based study. Ann Hepatol 2007; 6: 161-163.

11 Adams LA, Lymp JF, St Sauver J, Sanderson SO, Lindor KD, Feldstein A, Angulo P. The natural history of nonalcoholic fatty liver disease: a population-based cohort study. Gastroenterology 2005; 129: 113-121.

12 Akahoshi M, Amasaki Y, Soda M, Tominaga T, Ichimaru S, Nakashima E, Seto S, Yano K. Correlation between fatty liver and coronary risk factors: a population study of elderly men and women in Nagasaki, Japan. Hypertens Res 2001; 24: 337-343.

13 Shibata M, Kihara Y, Taguchi M, Tashiro M, Otsuki M. Nonalcoholic fatty liver disease is a risk factor for type 2 diabetes in middle-aged Japanese men. Diabetes Care 2007; 30: 2940-2944.

14 Targher G, Bertolini L, Padovani R, Rodella S, Tessari R, Zenari L, Day C, Arcaro G. Prevalence of nonalcoholic fatty liver disease and its association with cardiovascular disease among type 2 diabetic patients. Diabetes Care 2007; 30: 1212-1218.

15 Targher G, Bertolini L, Poli F, Rodella S, Scala L, Tessari R, Zenari L, Falezza G. Nonalcoholic fatty liver disease and risk of future cardiovascular events among type 2 diabetic patients. Diabetes 2005; 54: 3541-3546.

16 Akabame S, Hamaguchi M, Tomiyasu K, Tanaka M, Kobayashi-Takenaka Y, Nakano K, Oda Y, Yoshikawa T. Evaluation of vulnerable coronary plaques and non-alcoholic fatty liver disease (NAFLD) by 64-detector multislice computed tomography (MSCT). Circ J 2008; 72: 618-625.

17 Arslan U, Turkoglu S, Balcioglu S, Tavil Y, Karakan T, Cengel A. Association between nonalcoholic fatty liver disease and coronary artery disease. Coron Artery Dis 2007; 18: 433-436.

18 Hamaguchi M, Kojima T, Takeda N, Nagata C, Takeda J, Sarui H, Kawahito Y, Yoshida N, Suetsugu A, Kato T, Okuda J, Ida K, Yoshikawa T. Nonalcoholic fatty liver disease is a novel predictor of cardiovascular disease. World J Gastroenterol 2007; 13: 1579-1584.

19 Bedogni G, Miglioli L, Masutti F, Castiglione A, Croce LS, Tiribelli C, Bellentani S. Incidence and natural course of fatty liver in the general population: the Dionysos study. Hepatology 2007; 46: 1387-1391.

20 Hamaguchi M, Kojima T, Takeda N, Nakagawa T, Taniguchi H, Fujii K, Omatsu T, Nakajima T, Sarui H, Shimazaki M, Kato T, Okuda J, Ida K. The metabolic syndrome as a predictor of nonalcoholic fatty liver disease. Ann Intern Med 2005; 143: 722-728.

21 Ogihara T, Kikuchi K, Matsuoka H, Fujita T, Higaki J, Horiuchi M, Imai Y, Imaizumi T, Ito S, Iwao H, Kario K, Kawano Y, Kim-Mitsuyama S, Kimura G, Matsubara H, Matsuura H, Naruse M, Saito I, Shimada K, Shimamoto K, Suzuki H, Takishita S, Tanahashi N, Tsuchihashi T, Uchiyama M, Ueda S, Ueshima H, Umemura S, Ishimitsu T, Rakugi H. The Japanese Society of Hypertension Guidelines for the Management of Hypertension (JSH 2009). Hypertens Res 2009; 32: 3-107.

22 Matsuzawa Y, Ikeda Y, Katayama S, Kita T, Kugiyama K, Saito Y, Shimamoto K, Seino Y, Daida H, Teramoto T, Nakao K, Makino H, Miyazaki S, Yamada N, Fujita T, Nakamura T, Funahashi T. Definition and the diagnostic standard for metabolic syndrome-Committee to Evaluate Diagnostic Standards for Metabolic Syndrome. Nippon Naika Gakkai Zasshi 2005; 94: 794-809.

23 Yajima Y, Ohta K, Narui T, Abe R, Suzuki H, Ohtsuki M. Ultrasonographical diagnosis of fatty liver: significance of the liver-kidney contrast. Tohoku J Exp Med 1983; 139: 43-50.

24 Scatarige JC, Scott WW, Donovan PJ, Siegelman SS, Sanders RC. Fatty infiltration of the liver: ultrasonographic and computed tomographic correlation. J Ultrasound Med 1984; 3: 9-14.

25 Cohen J. A coefficient of agreement for nominal scales. Educ Psychol Meas 1960; 20: 37-46.

26 Young $\mathrm{R}$, Kerr $\mathrm{G}$ (eds). Reassessment of the atomic bomb radiation dosimetry for Hiroshima and Nagasaki-dosimetry system 2002. Hiroshima: Radiation Effects Research Foundation, 2005.

27 Pierce DA, Stram DO, Vaeth M. Allowing for random errors in radiation dose estimates for the atomic bomb survivor data. Radiat Res 1990; 123: 275-284.

28 Casey VA, Dwyer JT, Coleman KA, Valadian I. Body mass index from childhood to middle age: a 50-y follow-up. Am J Clin Nutr 1992; 56: 14-18.

29 Stevens J, Cai J, Pamuk ER, Williamson DF, Thun MJ, Wood JL. The effect of age on the association between body-mass index and mortality. N Engl J Med 1998; 338: $1-7$.

30 Akahoshi M, Amasaki Y, Soda M, Hida A, Imaizumi M, Nakashima E, Maeda R, Seto S, Yano K. Effects of radiation on fatty liver and metabolic coronary risk factors among atomic bomb survivors in Nagasaki. Hypertens Res 2003; 26: 965-970. 
31 Burgert TS, Taksali SE, Dziura J, Goodman TR, Yeckel CW, Papademetris X, Constable RT, Weiss R, Tamborlane WV, Savoye M, Seyal AA, Caprio S. Alanine aminotransferase levels and fatty liver in childhood obesity: associations with insulin resistance, adiponectin, and visceral fat. J Clin Endocrinol Metab 2006; 91 : 4287-4294.

32 Kishino T, Watanabe K, Urata T, Takano M, Uemura T, Nishikawa K, Mine Y, Matsumoto M, Ohtsuka K, Ohnishi H, Mori H, Takahashi S, Ishida H, Watanabe T. Visceral fat thickness in overweight men correlates with alterations in serum fatty acid composition. Clin Chim Acta 2008; 398: 57-62.
33 Nishina M, Kikuchi T, Yamazaki H, Kameda K, Hiura M, Uchiyama M. Relationship among systolic blood pressure, serum insulin and leptin, and visceral fat accumulation in obese children. Hypertens Res 2003; 26: 281-288.

34 Tamba S, Nishizawa H, Funahashi T, Okauchi Y, Ogawa T, Noguchi M, Fujita K, Ryo M, Kihara S, Iwahashi H, Yamagata K, Nakamura T, Shimomura I, Matsuzawa Y. Relationship between the serum uric acid level, visceral fat accumulation and serum adiponectin concentration in Japanese men. Intern Med 2008; 47: 1175-1180.

35 Brunt EM. Nonalcoholic steatohepatitis: definition and pathology. Semin Liver Dis 2001; 21: 3-16. 